\title{
A Novel Method for Indomethacin Determination Based on Graphene Loaded Nickel Oxides Nanoparticles Film
}

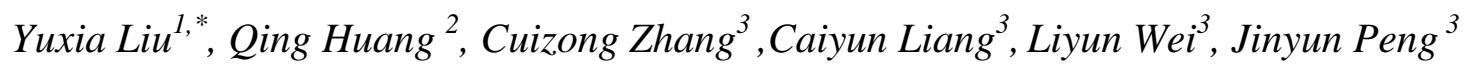 \\ ${ }^{1}$ College of Physics and Electronic Engineering, Guangxi Normal University for Nationalities, \\ Chongzuo 532200, China \\ ${ }^{2}$ School of Pharmacy, Henan University of Traditional Chinese Medicine, Zhengzhou 450046, China \\ ${ }^{3}$ College of Chemistry and Chemical Engineering, Guangxi Normal University for Nationalities, \\ Chongzuo 532200, China \\ *E-mail: liuyuxiayx@163.com
}

doi: $10.20964 / 2018.02 .39$

Received: 15 October 2017 / Accepted: 11 December 2017 / Published: 28 December 2017

\begin{abstract}
A novel method was described for sensitive voltammetric determination of indomethacin based on a graphene loaded nickel oxides nanoparticles (Gr-NiO) film by one-step electrodeposition. The asprepared electrode (Gr-NiO/GCE) was characterized by electrochemical methods and scanning electron microscopy. The electrocatalytic properties of $\mathrm{Gr}-\mathrm{NiO} / \mathrm{GCE}$ toward the oxidation of indomethacin were analyzed via cyclic voltammetry (CV) and differential pulse voltammetry (DPV). The results indicate that the one-step prepared Gr-NiO/GCE can remarkably enhance electrocatalytic activity towards the oxidation of indomethacin. Under optimized conditions, voltammetric response of $\mathrm{Gr}-\mathrm{NiO} / \mathrm{GCE}$ was linear to indomethacin within the concentration range of $2.0 \times 10^{-7}-7.0 \times 10^{-5} \mathrm{~mol} \mathrm{~L}^{-1}$, with the detection limit of $5.4 \times 10^{-8} \mathrm{~mol} \mathrm{~L}^{-1}(\mathrm{~S} / \mathrm{N}=3)$. And, the method was also applied to detect indomethacin in pharmaceutical dosage forms with wonderful satisfactory.
\end{abstract}

Keywords: Graphene; nickel oxides nanoparticles; Voltammetric sensor; indomethacin; determination

\section{FULL TEXT}

(C) 2018 The Authors. Published by ESG (www.electrochemsci.org). This article is an open access article distributed under the terms and conditions of the Creative Commons Attribution license (http://creativecommons.org/licenses/by/4.0/). 